\title{
Highly Efficient Binding of DNA on the Sidewalls and Tips of Carbon Nanotubes Using Photochemistry
}

2004

Vol. 4, No. 1

89-93

\author{
Minoo J. Moghaddam, ${ }^{\dagger}$ Sarah Taylor, ${ }^{\dagger}$ Mei Gao, ${ }^{\ddagger}$ Shaoming Huang, ${ }^{\ddagger}, \S$ \\ Liming Dai,,,$\| l$ and Maxine J. McCall ${ }^{*}, \dagger$ \\ CSIRO Molecular Science, PO Box 184, North Ryde, NSW 1670, Australia, and \\ CSIRO Molecular Science, Bag 10, Clayton South, Vic. 3169, Australia
}

Received October 20, 2003; Revised Manuscript Received November 10, 2003

\begin{abstract}
The sidewalls of vertically aligned, multiwalled carbon nanotubes were functionalized using azide photochemistry, and DNA oligonucleotides were synthesized in situ from the reactive group on each photoadduct to produce water-soluble DNA-coated nanotubes. The functional DNA sites on the nanotubes were visualized from gold nanoparticles modified with complementary DNA and using TEM. The sidewall functionalization enabled further DNA-directed modification of the nanotubes' surfaces with nanoparticles. The DNA-coated vertically aligned nanotubes offer the architecture for a highly loaded three-dimensional DNA chip.
\end{abstract}

Carbon nanotubes have enormous potential as components of nanoscale electronic devices and sensors because of their unique conducting properties and high thermal capacity. To readily manufacture these devices, methods for manipulating and positioning the nanotubes must be developed. Various methods are being explored, including masking, manipulating by AFM tips, and selective placement on chemically functionalized surfaces. ${ }^{1-4}$ The concept of using DNA to direct the assembly of nanotubes into nanoscale devices is also attracting attention ${ }^{5}$ because of its potential to assemble a multicomponent system in one step by using different base sequences for each component. To date, the focus in this area has been on placing DNA at the tips of nanotubes. ${ }^{6}$ To produce reactive sites to which the DNA may be attached, the nanotubes are mainly oxidized by acid treatment to introduce carboxyl groups on their tips; ${ }^{7}$ this procedure also introduces carboxyl groups at any defects in the sidewalls. ${ }^{8}$ DNA molecules with functional linkers are then coupled to the carboxyl groups on the nanotubes..$^{9-13}$ This chemistry has also been used to couple nanotubes with molecules such as PNA $^{6}$ and proteins. ${ }^{14}$

Carbon nanotubes functionalized with DNA all over their sidewalls, as opposed to those with DNA placed solely on their tips, would have certain advantages when being manipulated and positioned into nanoscale devices. First, a

\footnotetext{
* Corresponding author. E-mail: maxine.mccall@csiro.au.

CSIRO Molecular Science, North Ryde.

$\doteqdot$ CSIRO Molecular Science, Clayton.

$\S$ Present address: Chemistry Department, Duke University, Durham, North Carolina 27708.

"Present address: College of Polymer Science and Polymer Engineering, University of Akron, Akron, Ohio 44325.
}

coating of DNA confers a negative surface charge on the nanotubes that would produce a stable dispersion in the aqueous solutions required for DNA-directed assembly. In contrast, nanotubes functionalized with DNA only on their tips require the addition of a surfactant to prevent their aggregation in aqueous solutions due to hydrophobic interactions between their exposed surfaces. Second, the surface coating of DNA allows for flexibility in the lengths of nanotubes when using DNA to place a nanotube, for example, across two electrodes spotted with complementary DNA strands in a nanoscale electronic device. In contrast, the lengths of nanotubes with DNA on the tips must precisely match the spacings between the spots on the electrodes.

We have developed a mild and facile method for attaching single-stranded DNA to the sidewalls and tips of carbon nanotubes. The method uses azide-photochemistry to functionalize the sidewalls and tips of carbon nanotubes in a solidstate reaction, and the subsequent synthesis of a DNA oligonucleotide from the reactive group on each photoadduct. While cycloaddition of azides by thermolysis or photolysis to substrates containing double bonds is well-known, ${ }^{15}$ and azide-thermolysis has been used successfully in solution to functionalize fullerenes ${ }^{16,17}$ and the sidewalls of single-walled nanotubes (SWNT), ${ }^{18,19}$ this is the first report of azidephotolysis being used to functionalize carbon nanotubes.

To get good coverage of the photoadducts, and subsequently DNA, over the entire surface of each nanotube, it is necessary to use nanotubes that are initially discrete and cannot aggregate during the chemical reactions. To achieve this, we used vertically aligned, multiwalled carbon nano- 


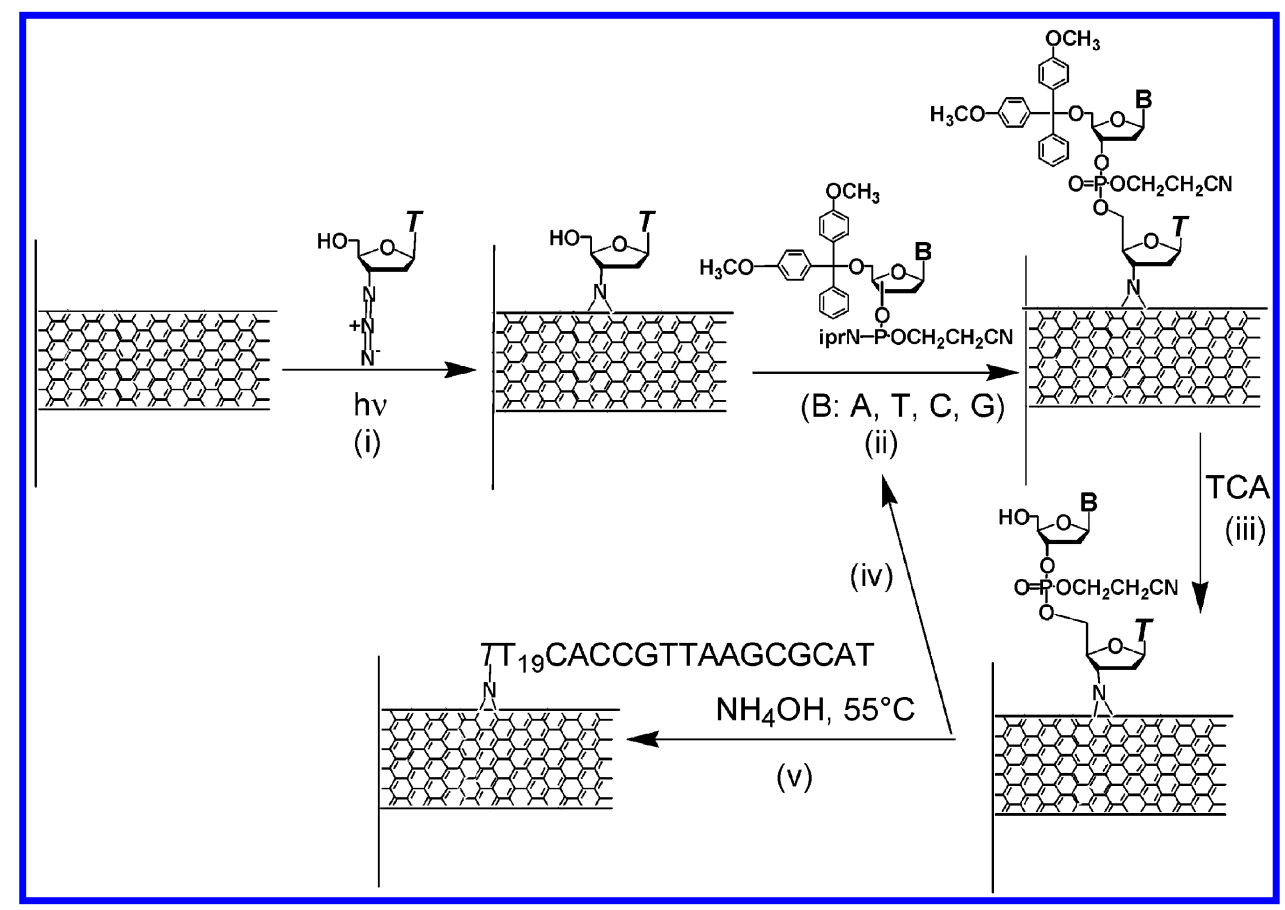

Figure 1. In situ DNA synthesis from sidewalls of carbon nanotubes photoetched with azidothymidine. Aligned MWNTs on a solid support are coated with a solution of AZT and are UV irradiated to produce photoadducts, each with a hydroxyl group (i). The hydroxyl group reacts with a phosphoramidite mononucleotide to initiate synthesis of the DNA molecule (ii). Trichloroacetic acid deprotects the hydroxyl group (iii) for reaction with the next nucleotide (iv) and the cycle is repeated until the molecule with desired base-sequence is made. Finally, the supported nanotubes are heated in ammonia solution to remove blocking groups from the nucleotides (v) to produce DNA-coated nanotubes.

tubes (MWNTs) on a solid support ${ }^{20}$ where the spacings between individual nanotubes can be controlled by the density of the catalyst on the support. While we used aligned MWNTs, discrete single-walled nanotubes also could be used as substrates. ${ }^{21-22}$ Our vertically aligned MWNTs were grown on a quartz substrate by pyrolysis of iron(II) phthalocyanine (Aldrich) under $\mathrm{Ar} / \mathrm{H}_{2}$ at $800-1100$ ${ }^{\circ} \mathrm{C} .{ }^{20}$ The exposed ends of the nanotubes were then sputtered with gold to form a thin coating on their tips. After a 1-2 min exposure to $48 \%$ hydrofluoric acid (Aldrich) (caution: avoid inhalation, ingestion, and skin and eye contact), the nanotubes supported on gold foil were peeled off the quartz substrate and washed several times with water. ${ }^{20}$ This produced nanotubes with ends free of amorphous carbon deposits.

The aligned MWNTs, supported on gold foil approximately $25 \mathrm{~mm}^{2}$ in area, were coated with $20 \mu \mathrm{L}$ of ethanol containing $100-250 \mu \mathrm{g}$ of the photoactive molecule azidothymidine (AZT, Sigma Chemical Company), and left to dry at room temperature. The sample was UV-irradiated for 5 min using a $450 \mathrm{~W}$ medium-pressure xenon lamp with maximum output of $112 \mathrm{~mW} / \mathrm{cm}^{2}$ at $254 \mathrm{~nm}$ (Figure 1, step (i)). The irradiation causes the formation of very active nitrene groups in the vicinity of the carbon lattice. In a cycloaddition reaction, these nitrene groups couple to the nanotubes and form aziridine photoadducts. ${ }^{23}$ Thus, a very high loading of the aziridine adducts is photoetched on the nanotubes' sidewalls and tips in this solid-phase reaction. The samples then were washed thoroughly with ethanol to remove unreacted AZT. The efficiency of removal of unreacted AZT was assessed by monitoring the wash solutions using HPLC.

The gold-supported sample of aligned MWNTs, photoetched with AZT, was placed in a clean, empty, reaction chamber of an automated DNA synthesizer (Applied Biosystems 394 DNA/RNA Synthesizer, Foster City, CA), and a 35-nucleotide DNA molecule of defined base sequence was built in situ by sequential addition of protected nucleotides using standard phosphoramidite chemistry with coupling time extended to 5 min (Figure 1, steps ii-iv). Here, the free hydroxyl group at the $5^{\prime}$ position of the deoxyribose moiety in each aziridothymidine group was used as the site of attachment from which each DNA molecule was built. Thus, the process by which the DNA is made is identical to that used by commercial suppliers of oligonucleotides, except that in our process the nanotubes on gold foil, functionalized with the thymidine group, replace the standard solid support functionalized with the desired $3^{\prime}$ nucleotide.

Following the synthesis, the protecting groups were removed from functional groups on the DNA strands by exposing the nanotube sample to $28 \%$ ammonia solution (Univar) at $55^{\circ} \mathrm{C}$ for $8 \mathrm{~h}$ (Figure 1, step (v)). After cooling, the supernatant was removed and the sample was rinsed thoroughly with several changes of autoclaved milliQ water until the $\mathrm{pH}$ of the wash solution was less than 7. At no time during this procedure were the nanotubes allowed to become dry. The DNA-modified nanotubes were stored under sterile water at $4{ }^{\circ} \mathrm{C}$. When required for further use, the DNA-modified nanotubes were sonicated for 3-5 min in an ultrasonic cleaner (model FX8, Unisonics, Sydney), 


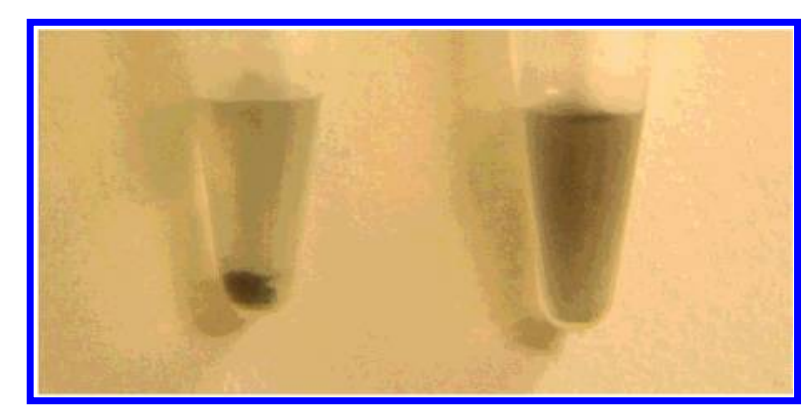

Figure 2. DNA-modified MWNTs form a stable suspension in water. Unmodified MWNTs (left) and DNA-modified MWNTs (right) supported on gold foil were placed in water, sonicated for $5 \mathrm{~min}$, and left to stand for $1 \mathrm{~h}$ before this image was taken.

which released them from the gold foil to form a stable suspension in water (see Figure 2).

In this experiment, the base sequence of the 35 -nucleotide DNA molecules attached to the walls of the nanotubes is $5^{\prime}$ TACGCGAATTGCCAC(T) ${ }_{19} T 3^{\prime}$. Here, the $T$ at the $3^{\prime}$ end of each molecule is the deoxyribose-thymine which is photoetched to the exposed surface of the nanotube, and which was generated by photochemical reaction of AZT.

When attempting to bind DNA to defined locations on nanotubes, it is important to check if the DNA has been attached as expected in the desired locations, for example, at the tips or on the sidewalls. Therefore, we have developed a visual assay using DNA-modified gold nanoparticles and transmission electron microscopy (TEM) to determine the locations of the DNA molecules on the carbon nanotubes. The assay relies on short, single strands of DNA, attached to gold nanoparticles, binding to the single strands of DNA (of complementary base sequence) on the nanotubes. Thus the assay determines DNA molecules on the nanotubes that are functional (i.e., are able to bind their complementary strand), and their locations are revealed in TEM images by gold nanoparticles positioned in close proximity to the surfaces of the nanotubes.

Gold nanoparticles were prepared according to the method of Frens ${ }^{24}$ with diameters of $15-16 \mathrm{~nm}$ as measured by TEM. DNA molecules, with disulfide linkers on their $3^{\prime}$ ends for binding to the gold nanoparticles, were synthesized on the DNA/RNA synthesizer, using protected DNA phosphoramidite monomers and 3'-disulfide-linker on solid support purchased from Glen Research (Sterling, Virginia). After synthesis, the oligonucleotides were removed from the solid support by exposure to $28 \%$ ammonia solution at room temperature for $30 \mathrm{~min}$, and then processed further and checked for purity according to methods described for standard DNA oligonucleotides. ${ }^{25}$ This molecule (DNA*), which has the composition 5' AGTGGCAATTCGCGTA$\left(\mathrm{CH}_{2}\right)_{3}-\mathrm{S}-\left[\mathrm{S}-\left(\mathrm{CH}_{2}\right)_{3}-\mathrm{OH}\right]$, was chemisorbed to the gold nanoparticles using a procedure essentially as described by Storhoff et al., ${ }^{26}$ except that the disulfide linker was not reduced to a terminal sulfydryl, and the ratio of DNA to gold nanoparticles was increased by a factor of 2 .

To perform the assay with controls, four samples of aligned MWNTs on gold foil, each approximately $25 \mathrm{~mm}^{2}$, were tested. Two samples were photoetched with AZT and subjected to in situ DNA synthesis as described, while the other two samples were left unmodified. All samples were separately preincubated for a total of $90 \mathrm{~min}$ in three exchanges of $\sim 50 \mu \mathrm{L}$ ExpressHyb (Palo Alto, CA) at $37{ }^{\circ} \mathrm{C}$ before a freshly prepared solution of ExpressHyb containing either DNA-modified gold nanoparticles $(20 \mu \mathrm{L}$ of $10 \mathrm{nM}$ DNA*-gold nanoparticles in $0.1 \mathrm{M} \mathrm{NaCl}, 10 \mathrm{mM}$ sodium phosphate, $\mathrm{pH} 7$, mixed with $30 \mu \mathrm{L}$ ExpressHyb) or unmodified gold nanoparticles $(20 \mu \mathrm{L}$ of $10 \mathrm{nM}$ gold nanoparticles mixed with $30 \mu \mathrm{L}$ ExpressHyb) was added to the samples. The samples were rocked gently either for $6 \mathrm{~h}$ or overnight at $37^{\circ} \mathrm{C}$. Supernatants were then removed, and the samples were washed three times at room temperature with $100 \mu \mathrm{L} 0.1 \mathrm{M} \mathrm{NaCl}, 10 \mathrm{mM}$ sodium phosphate buffer, $\mathrm{pH} 7$, before storing at $4{ }^{\circ} \mathrm{C}$ in $100 \mu \mathrm{L}$ of $0.05 \mathrm{M} \mathrm{NaCl}, 10$ $\mathrm{mM}$ sodium phosphate buffer, $\mathrm{pH} 7$. To visualize the samples by TEM, nanotubes were removed from the gold support by scraping or brief sonication. Once dispersed, $1.5 \mu \mathrm{L}$ of solution was placed on a 200-mesh copper grid prepared with carbon film and left to air-dry. Grids were then placed in the TEM (Philips CM100) and digital images taken with a Gatan Dual Vision camera.

In this assay, the 16 nucleotides in the DNA* molecules bound to gold nanoparticles can form Watson-Crick base pairs with the 16 nucleotides at the $5^{\prime}$ end of the 35 nucleotide DNA molecules attached to carbon nanotubes. Figure 3a shows gold nanoparticles covering most of the outer surface of the nanotubes, indicating that photochemical coupling of the AZT to the nanotubes was indeed extensive and subsequent synthesis of DNA from this moiety was efficient. Note that the gold nanoparticles of $15 \mathrm{~nm}$ diameter are far larger than the $2 \mathrm{~nm}$ cross-sectional diameter of a double-helical DNA molecule. Thus, the average surface coverage, calculated from Figure 3a, of approximately 1000 gold nanoparticles per $\mu \mathrm{m}^{2}$ (or over 3000 nanoparticles on an individual multiwalled nanotube of diameter $100 \mathrm{~nm}$ and length $10 \mu \mathrm{m}$ ) reveals a lower estimate for the number of functional DNA molecules on each nanotube.

Figures $3 \mathrm{~b}$ and $3 \mathrm{~d}$ represent control experiments showing that unmodified gold nanoparticles do not bind to DNAmodified carbon nanotubes, nor to unmodified nanotubes, respectively, under the assay conditions. Figure $3 \mathrm{c}$ is the control to check for nonspecific binding of DNA-modified gold nanoparticles to unmodified nanotubes. It is known that DNA will stick strongly to unmodified nanotubes through physical adsorption, ${ }^{27-29}$ and the same is true for DNAmodified gold nanoparticles (not shown). The inclusion of a surfactant, such as the commercially available ExpressHyb, which is commonly used to limit nonspecific binding in molecular biological reactions, reduces nonspecific binding of DNA-modified gold nanoparticles to unmodified nanotubes in our assay (Figure 3c).

In addition to providing a means for easier manipulation of nanotubes in aqueous solutions and positioning them in devices, functionalization of the sidewalls of carbon nanotubes with DNA offers a finely controlled method for assembling surface coatings on the nanotubes (for example, on ordered arrays of nanotubes for photonics applications ${ }^{30}$ ) 


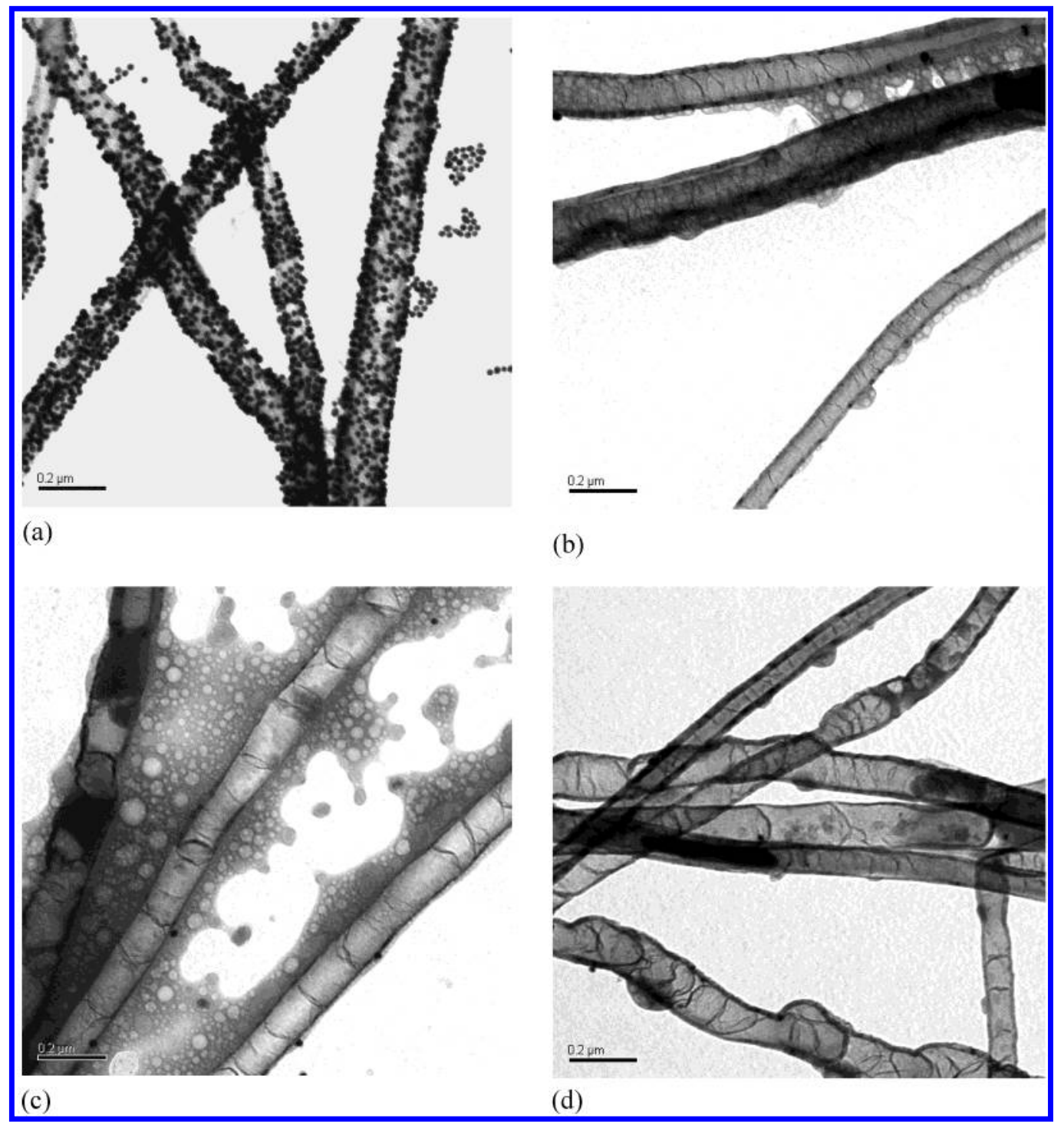

Figure 3. Visual assay for determining the sites of attachment of DNA to carbon nanotubes, using gold nanoparticles functionalized with DNA of complementary base sequence (DNA*), and imaging by TEM. (a) Nanotubes-DNA with DNA*-gold nanoparticles, (b) NanotubesDNA with unmodified gold nanoparticles, (c) unmodified nanotubes with DNA*-gold nanoparticles, (d) unmodified nanotubes with unmodified gold nanoparticles. The diameter of the gold nanoparticles is $15-16 \mathrm{~nm}$. Scale bar is $200 \mathrm{~nm}$.

in order to alter their surface properties. For example, the nanotubes may be covered with a monolayer of gold nanoparticles (or other DNA-modified nanoparticles) as demonstrated in Figure 3a. Further, the remaining, unbound single-strands of DNA on the nanoparticles attached to the nanotubes could be used to build up additional layers of gold or different nanoparticles. To demonstrate the feasibility of this approach, we synthesized DNA molecules of composition $5^{\prime}$ TACGCGAATTGCCACT $-\left(\mathrm{CH}_{2}\right)_{3}-\mathrm{S}-\left[\mathrm{S}-\left(\mathrm{CH}_{2}\right)_{3}-\right.$ $\mathrm{OH}]$ and bound them to gold nanoparticles of $38 \mathrm{~nm}$ diameter following the procedures described above. Then we added these DNA-modified gold nanoparticles, in the presence of ExpressHyb, to a sample of MWNTs coated with gold nanoparticles of $16 \mathrm{~nm}$ diameter prepared exactly as described for the sample in Figure 3a. The base sequences of the DNA molecules are such that the DNA attached to the larger nanoparticles (38 $\mathrm{nm}$ diameter) can bind to the DNA on the smaller nanoparticles (16 $\mathrm{nm}$ diameter), but not to the DNA on the nanotubes. The TEM image shown in Figure 4 demonstrates that the approach is viable. Optimization of the lengths of the DNA molecules should provide a more uniform surface coating for each layer of nanoparticles.

Furthermore, our photochemical method for attaching DNA to nanotubes on a solid support could be combined with photolithographic methods to produce patterns of DNA of different sequences on the nanotubes, for use as DNA chips in genomic research or for DNA sensors. The use of nanotubes in this way would result in a single site on an array surface effectively immobilizing thousands of DNA molecules. Conventional array technology can only immobilize one DNA molecule per surface site. In addition, the erect nature of the nanotubes ensures that the immobilized DNA is held off the array surface to create a 3-dimensional array, and thus the DNA is also highly available for hybridization. This combination of high loading and high availability of DNA molecules on the surface of individual 


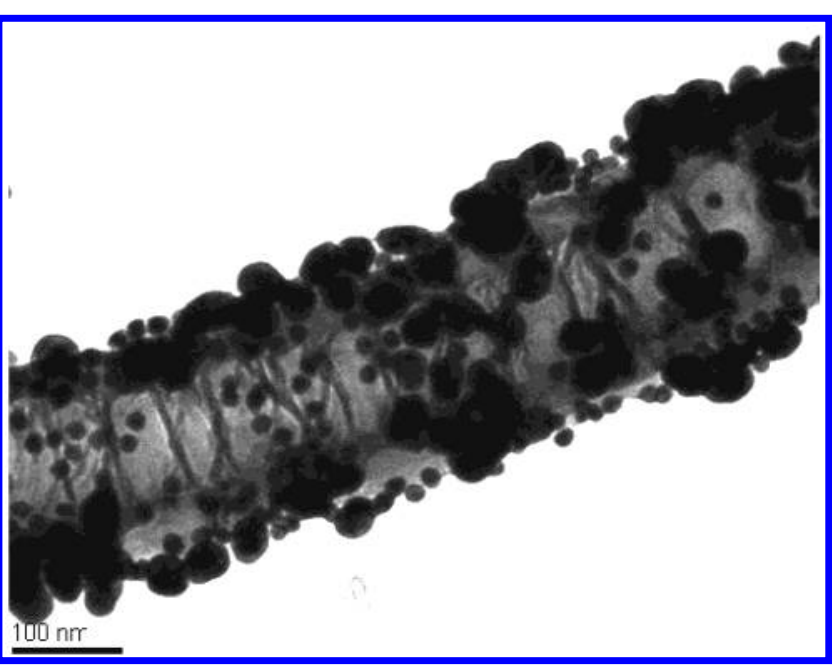

Figure 4. DNA-directed modification of the surfaces of carbon nanotubes with layers of gold nanoparticles of different diameters. The sample in this TEM image was prepared in four steps as follows: (i) photochemical functionalization of the sidewall of the nanotube with AZT; (ii) in situ DNA synthesis from AZT; (iii) binding of the DNA on the nanotubes to complementary DNA* attached to gold nanoparticles of $16 \mathrm{~nm}$ diameter; and (iv) binding of the remaining unbound DNA* (on $16 \mathrm{~nm}$ gold nanoparticles) to complementary DNA attached to gold nanoparticles of $38 \mathrm{~nm}$ diameter. Scale bar is $100 \mathrm{~nm}$.

nanotubes means that very few nanotubes would suffice for each DNA sequence, and therefore the DNA chips or sensors could be miniaturized to the extreme.

Acknowledgment. We thank B. Raguse, G. Wei, and J. Myer for gifts of gold nanoparticles, R. Letsinger, W. Parak, D. Zanchet, and P. Alivisatos for advice on binding DNA to gold nanoparticles, and G. Simpson and J. O'Connell for support.

\section{Note Added after ASAP Posting}

This paper was released ASAP on 12/9/2003 with a standard copyright. It has been corrected to a crown copyright. The correct version was posted on 12/30/2003.

\section{References}

(1) Burghard, M.; Duesberg, G.; Philipp, G.; Muster, J.; Roth, S. $\underline{A d v}$. Materials 1998, 10, 584.

(2) Liu, J.; Casavant, M. J.; Cox, M.; Walters, D. A.; Boul, P.; Lu, W.; Rimberg, A. J.; Smith, K. A.; Colbert, D. T.; Smalley; R. E. Chem. Phys. Lett. 1999, 303, 125.

(3) Avouris, Ph.; Hertel, T.; Martel, R.; Schmidt, T.; Shea, H. R.; Walkup, R. E. Appl. Surf. Sci. 1999, 141, 201.
(4) Lewenstein, J. C.; Burgin, T. P.; Ribayrol, A.; Nagahara, L. A.; Tsui, R. K. Nano Lett. 2002, 2, 443.

(5) Tsui, R.; Siragusa, L.; Goronkin, H. C. R. Acad. Sci. Paris 2000 , t.1, Ser. IV, 875

(6) Williams, K. A.; Veenhuizen, P. T. M.; de la Torre, B. G.; Eritja, R.; Dekker, C. Nature 2002, 420, 761.

(7) Liu, J.; Rinzler, A. G.; Dai, H.; Hafner, J. H.; Bradley, R. K.; Boul, P. J.; Lu, A.; Iverson, T.; Shelimov, K.; Huffman, C. B.; RodriguezMacias, F.; Shon, Y.-S.; Lee, T. R.; Colbert, D. T.; Smalley, R. E. Science 1998, 280, 1253.

(8) Chen, J.; Hamon, M. A.; Hu, H.; Chen, Y.; Rao, A. M.; Eklund, P. C.; Haddon, R. C. Science 1998, 282, 95.

(9) Nguyen, C. V.; Delzeit, L.; Cassell, A. M.; Li, J.; Han, J.; Meyyappan, M. Nano Lett. 2002, 2, 1079.

(10) Baker, S. E.; Cai, W.; Lasseter, T. L.; Weidkamp, K. P.; Hamers, R. J. Nano Lett. 2002, 2, 1413.

(11) Dwyer, C.; Guthold, M.; Falvo, M.; Washburn, S.; Superfine, R.; Erie, D. Nanotechnology 2002, 13, 601.

(12) Hazani, M.; Naaman, R.; Hennrich, F.; Kappes, M. M. Nano Lett. 2003, 3, 153 .

(13) Cai, H.; Cao, X.; Jiang, Y.; He, P.; Fang, Y. Anal. Bioanal. Chem 2003, 375, 287.

(14) Huang, W.; Taylor, S.; Fu, K.; Lin, Y.; Zhang, D.; Hanks, T. W.; Rao, A. M.; Sun, Y.-P. Nano Lett. 2002, 2, 311.

(15) Advanced Organic Chemistry: Reactions, Mechanisms, and Structure, 4th ed.; March, J., Ed.; Wiley-Interscience: New York, 1992.

(16) Prato, M.; Chan Li, Q.; Wudl, F.; Lucchini, V. J. Am. Chem. Soc. $1993,115,1148$

(17) Averdung, J.; Mattay, J.; Jacobi, D.; Abraham, W. Tetrahedron 1995, 51,2543

(18) Holzinger, M.; Vostrowsky, O.; Hirsch, A.; Hennrich, F.; Kappes, M.; Weiss, R.; Jellen, F. Angew. Chem.. Int. Ed. 2001, 40, 4002.

(19) Pantarotto, D.; Partidos, C. D.; Graff, R.; Hoebeke, J.; Briand, J.-P.; Prato, M.; Bianco, A. J. Am. Chem. Soc. 2003, 125, 6160.

(20) Huang, S.; Dai, L.; Mau, A. W. H. J. Phys. Chem. B 1999, 103, 4223

(21) Kong, J.; Soh, H. T.; Cassell, A. M.; Quate, C. F.; Dai, H. $\underline{\text { Nature }}$ 1998, 395, 878.

(22) Huang, S.; Cai, X.; Liu, J. J. Am. Chem. Soc. 2003, 125, 5636.

(23) Yasuda, N.; Yamamoto, S.; Wada, Y.; Yanagida, S. J. Polvm. Sci. Part A: Polvm. Chem. 2001, 39, 4196.

(24) Frens, G. Nature 1973, 241, 20.

(25) McCall, M. J.; Hendry, P.; Jennings, P. Proc. Natl. Acad. Sci. U.S.A 1992, 89, 5710.

(26) Storhoff, J. J.; Elghanian, R.; Mucic, R. C.; Mirkin, C. A.; Letsinger, R. L. J. Am. Chem. Soc. 1998, 120, 1959.

(27) Tsang, S. C.; Guo, Z.; Chen, Y. K.; Green, M. L. H.; Hill, H. A. O.; Hambley, T. W.; Sadler, P. J. Angew. Chem., Int. Ed. Engl. 1997, 36,2198

(28) Buzaneva, E.; Karlash, A.; Yakovkin, K.; Shtogun, Y.; Putselyk, S.; Zherebetskiy, D.; Gorchinskiy, A.; Popova, G.; Prilutska, S.; Matyshevska, O.; Prilutskyy, Y.; Lytvyn, P.; Scharff, P.; Eklund, P. Mater. Sci. Eng. C 2002, 19, 41.

(29) Zheng, M.; Jagota, A.; Semke, E. D.; Diner, B. A.; McLean, R. S.; Lustig, S. R.; Richardson, R. E.; Tassi, N. G. Nature Materials 2003, 2, 338 .

(30) Kempa, K.; Kimball, B.; Rybczynski, J.; Huang, Z. P.; Wu, P. F.; Steeves, D.; Sennett, M.; Giersig, M.; Rao, D. V. G. L. N.; Carnahan, D. L.; Wang, D. Z.; Lao, J. Y.; Li, W. Z.; Ren, Z. F. Nano Lett. 2003, 3, 13 .

NL034915Y 